\title{
Severe oesophageal injury caused by Steradent
}

\author{
G.R. Barclay and N.D.C. Finlayson \\ Gastrointestinal and Liver Service, Royal Infirmary, Edinburgh EH3 9YW, UK.
}

\begin{abstract}
Summary: An elderly woman swallowed 2 tablets of a denture-cleansing agent (Steradent) believing them to be her sleeping tablets. This caused severe burning pain in the throat and resulted in a tight postcricoid oesophageal stricture. Treatment by repeated dilatation of the stricture has been only partially successful. Characteristic containers for non-medicinal tablets might help those with poor vision, and medicinal and non-medicinal tablets should never be stored in the same place.
\end{abstract}

\section{Introduction}

Drugs taken orally in tablet form are recognized causes of oesophageal injury (Collins et al., 1979), but there have been few reports of oesophageal injury due to ingestion of tablets of nontherapeutic agents. Such reports have related mainly to accidental swallowing of Clinitest tablets by children and adults (Danzig \& Loebel, 1965). Abramson et al. (1974) have reported oral injury from ingestion of denture-cleansing powder (Denalan), and MacAuley et al. (1984) have reported widespread upper gastrointestinal ulceration in a patient who died ten days after swallowing denture-cleansing tablets (Steradent). We describe here a patient who sustained a severe oesophageal stricture from swallowing Steradent tablets accidentally, and we are not aware that this has been reported before.

\section{Case report}

A 74 year old woman accidentally swallowed 2 Steradent tablets instead of her usual sleeping tablets. She felt the tablets sticking in her throat and she then developed severe burning pain in the post-cricoid area; the next day she had severe pain on swallowing, followed by rapidly progressive dysphagia for solids and liquids, so that on admission to hospital two months later she could swallow only melted ice cream. She had lost one stone $(6.4 \mathrm{~kg})$ in weight over this period. She had had a duodenal ulcer diagnosed 25 years before, but she had never experienced heartburn or dysphagia prior to swallowing her Steradent tablets. She also suffered from diabetes mellitus,

G.R. Barclay, M.B., Ch.B., M.R.C.P.(UK); N.D.C. Finlayson, F.R.C.P.(Edin.), F.R.C.P.(Lond.)

Correspondence: N.D.C. Finlayson

Accepted: 4 July 1984 managed by diet alone, and chronic bronchitis. Her drug therapy included Benylin expectorant, theophylline, bendrofluazide and potassium chloride (Neo-Naclex-K), and nitrazepam for sleeping; she had taken these drugs regularly for several years but had had to stop them all on the day after swallowing the Steradent tablets because of dysphagia. She did not smoke or drink alcohol. Physical examination showed no significant abnormality.

Her peripheral blood count, blood urea, electrolyte concentrations and chest radiograph were normal. A barium swallow showed a tight oesophageal stricture in the post-cricoid region (Figure 1). Its site and benign nature was confirmed at fibreoptic endoscopy, the instrument being inserted carefully under direct vision. The lumen of the stricture was approximately $2 \mathrm{~mm}$ in diameter. Over the last three years several attempts have been made to dilate the stricture, only some of which have been successful. The biggest dilatation stretched the stricture to $7.3 \mathrm{~mm}$ diameter but resulted in an oesophageal rupture from which she nearly died. Currently she can swallow only liquids and blended food.

\section{Comment}

Our patient developed a severe post-cricoid oesophageal stricture after swallowing 2 Steradent tablets. It seems certain that the known corrosive effects of this agent were the cause of the oesophageal injury, as she experienced severe post-cricoid pain and pain on swallowing immediately after taking the tablets, followed within hours by rapidly progressive dysphagia. The severity of the injury has prevented biopsy of the oesophagus below the stricture, but it is highly unlikely that it was due to gastro-oesophageal reflux in view of the above sequence of events, the post-cricoid site of 


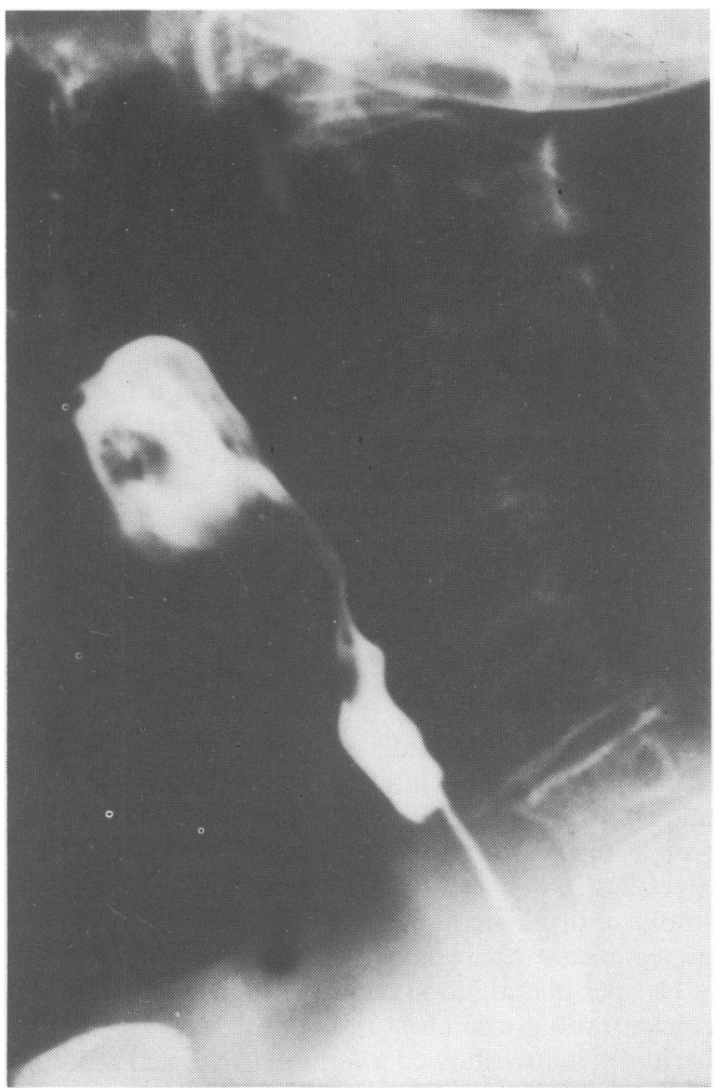

Figure 1 A barium swallow examination showing a narrow localized stricture in the post-cricoid (level of C7/ $\mathrm{T} 1$ vertebrae) region.

the stricture, and the absence of previous heartburn or dysphagia. The drugs she was taking are also unlikely to have caused the stricture, as she had taken them all regularly and without trouble for years, and stopping

\section{References}

ABRAMSON, A.L., EASON, R.L., PRYOR, W.H. \& MESSER, E.J. (1975). Upper digestive tract burns caused by Denalan denture cleanser powder. Annals of Otology, Rhinology and Laryngology, 84, 102.

ABRAMSON, A.L. (1978). Corrosive injury of the esophagus. Archives of Otolaryngology, 104, 514.

COLLINS, F.J., MATTHEWS, H.R., BAKER, S.E. \& STRAK- these drugs after dysphagia developed did not result in any improvement. Malignant disease was excluded as the cause of the stricture by endoscopy and by follow up for 30 months.

Abramson et al. (1974) reported oral injury due to dental-cleansing powder. They warned of the potential danger of denture-cleansing tablets, and Abramson (1978) subsequently demonstrated experimentally that such tablets caused localized oesophageal injury in contrast to the diffuse burn caused by denture powders. Steradent is a denture-cleansing agent in tablet form, and its active ingredient is perborate oxygen bleach with alkaline phosphate material. It forms a strongly alkaline solution, the caustic properties of which are due to chemical reactions which generate high concentrations of hydrogen peroxide. This causes liquefactive necrosis of the oesophagus, with deep penetration, resulting in severe damage (Abramson, 1978). MacAuley et al. (1984) have reported recently finding widespread upper gastrointestinal ulceration at necropsy in a woman who died ten days after swallowing 7 Steradent tablets accidentally. Our patient swallowed fewer tablets and did not die. She felt the tablets stick in her throat, and it is not surprising that in her case an oesophageal stricture developed, as this would have caused the oesophageal mucosa to be exposed to a high concentration of the chemical.

The disastrous consequences of swallowing Steradent emphasize how important it is that tabletso such as Clinitest and Steradent should not be kept in the same place as medicinal tablets. Manufacturers might consider putting warnings to this effect on their containers, especially when tablets look like medicinal tablets and are provided in containers similar to medicines, as in the case of Steradent. Elderly people, who often have impaired eyesight, would also be helped if containers of non-medicinal tablets could be identified easily by palpable ridges, as in the case of the Clinitest container.

OVA, J.M. (1979). Drug-induced oesophageal injury. British Medical Journal, 1, 1673.

DANZIG, L.S. \& LOEBEL, A.S. (1965). Clinitest-tablet ingestion and stricture of the esophagus. Journal of the American Medical Association, 192, 1092.

MACAULEY, D., O'BRIEN, I. ET AL. (1984). Fatal poisoning with denture cleaner. British Medical Journal, 288, 830. 